\title{
A NEW SKIPPER FOR SASKATCHEWAN
}

RONALD R. HOOPER, Museum of Natural History, 2340 Albert Street, Regina, Saskatchewan. S4P 3V7

On 21 June 1991, I attended the official opening of the Rendek Elm Forest, east of Erwood, Saskatchewan. Late in the afternoon, after everything was over, my brother Donald, Les Baker, and I took a drive. We went farther east and drove north of Armit.

We stopped along a marshy area where the Flat-topped Aster (Aster umbellatus) grows. This is the food plant of a beautiful orange butterfly known as the Harris' Checkerspot (Charidryas harrisii (Scudder)). This is the most northern locality where this species is found.

When we continued northward to the Red Deer River I discovered a specimen of the Silver-spotted Skipper (Epargyreus clarus (Cramer)). This is Saskatchewan's most northeastern record for this species.

Near the river, we saw a scolding Winter Wren, so my brother Donald and I decided to return the next day to look for its nest. We did not find the nest, but along the edge of a Jack Pine and aspen wood I collected Saskatchewan's first record of the Pepper and Salt Skipper (Amblyscirtes hegon (Scudder)). It was quite worn, but still recognizable. This brings the list of Saskatchewan skippers to 34 species.

The Pepper and Salt Skipper occurs in the woodlands from

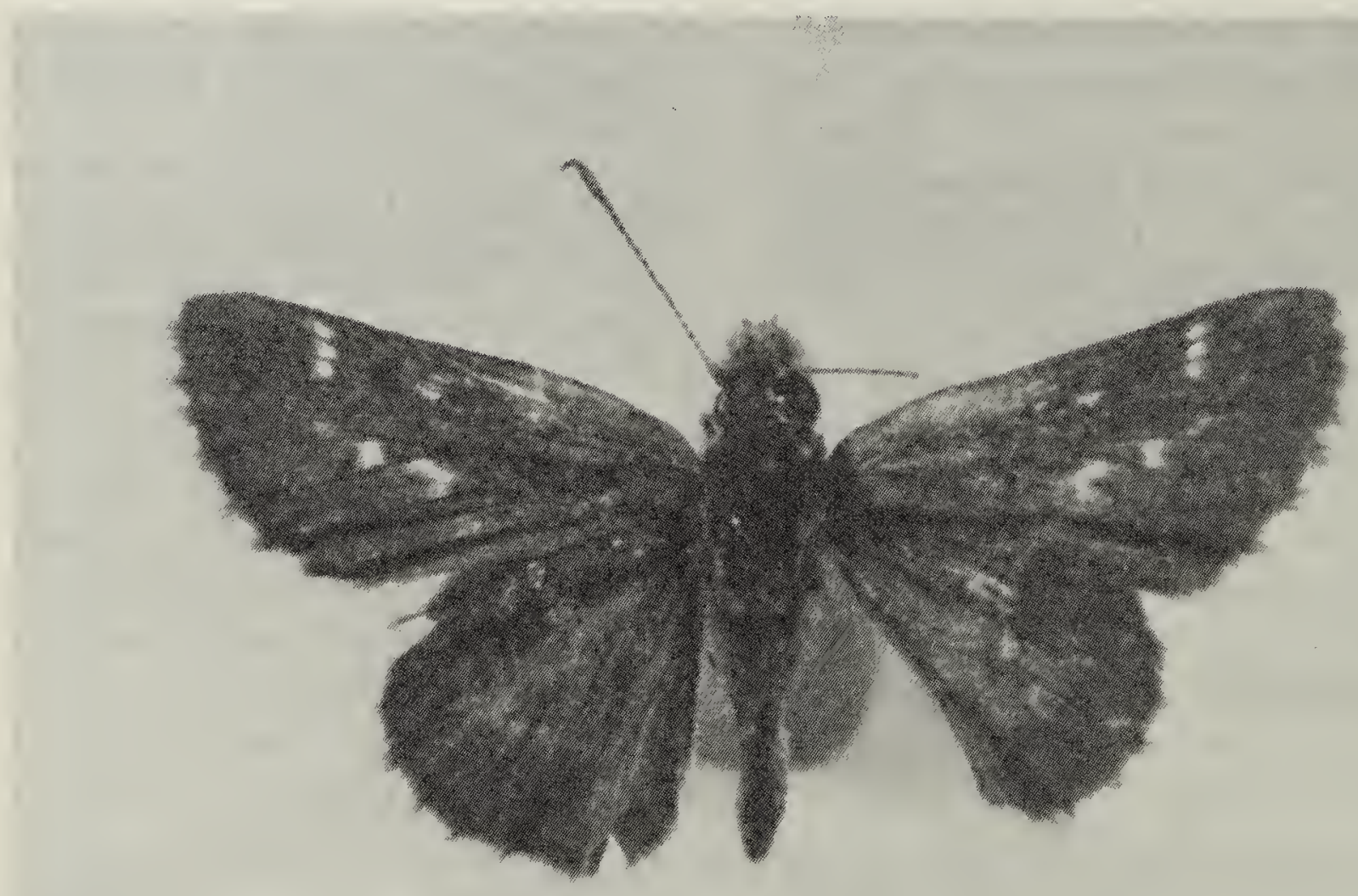




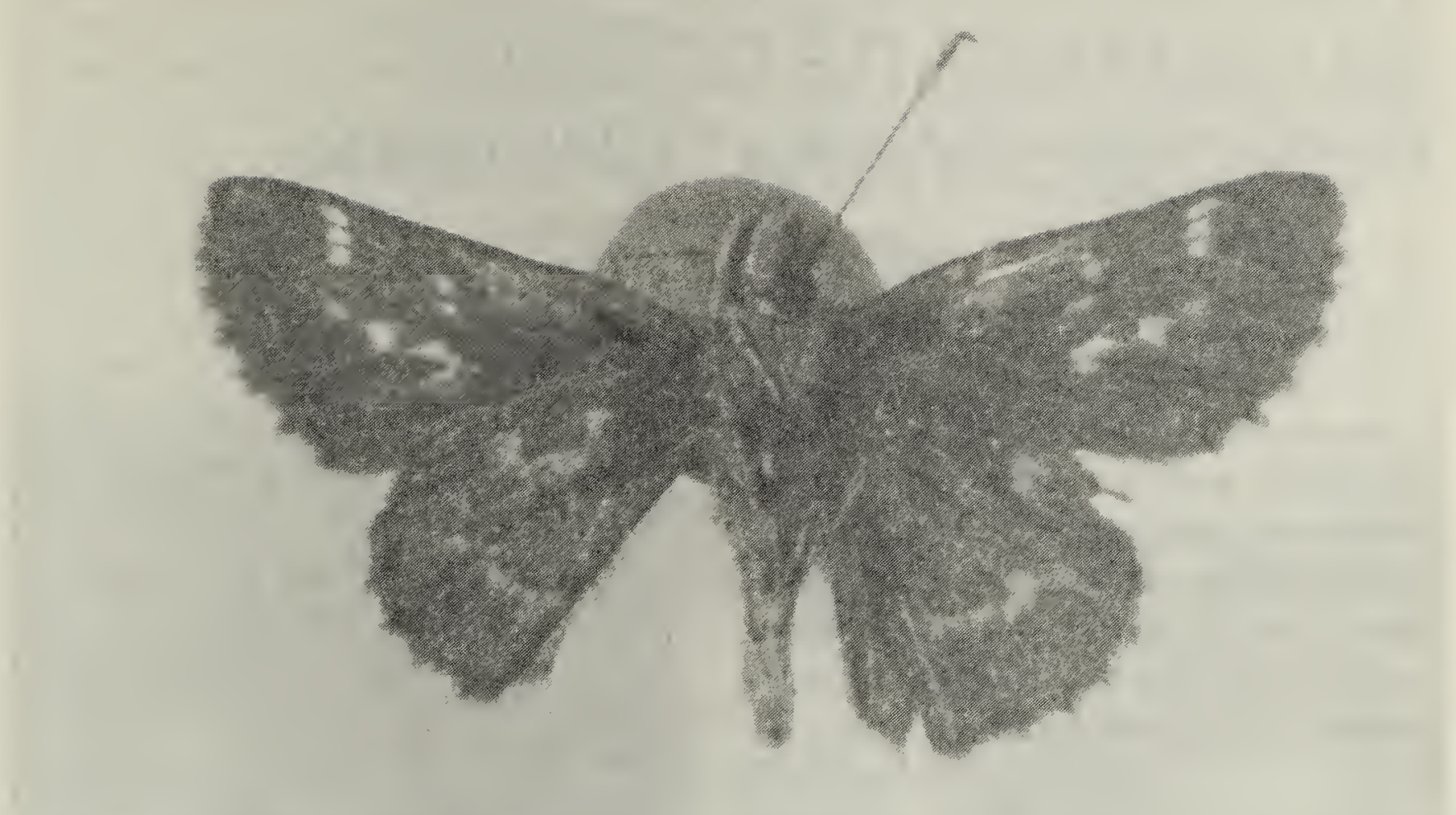

Pepper and Salt Skipper (underside), Manitoba

Keith Roney

eastern Canada to the Riding Moun- Skipper.

tains of Manitoba.

The Pepper and Salt Skipper is quite similar to the Roadside Skipper (Amblyscirtes vialis (Edwards)), and can be easily confused with it. It differs in having only three subapical white spots on the forewing; the Roadside Skipper usually has some white streaks above the uppermost spot. It also has two spots below the subapical spots toward the median area of the wing. The lowest one of these spots is rather long and curved; these spots are generally smaller or absent on the Roadside

The underside of the hind wing is dusted with pale greenish on fresh specimens. There is a pale streaking along the veins, and a pale band crosses the wing a little outward from the median area. The underside of the hind wing on the Roadside Skipper has a definite band right across the wing.

Fresh specimens of the Pepper and Salt Skipper should be found in Saskatchewan in late May and early June.

No species but man, so far as is known, unaided by circumstance or climatic change, has ever extinguished another, and certainly no species has ever devoured itself, an accomplishment of which man appears quite capable. Peter Mattiessen. 1959. Wildlife in America. Viking, NY. 